\title{
EDUCACIÓN EMOCIONAL EN CLAVE DE INTEGRACIÓN. UNA APORTACIÓN A LA INNOVACIÓN EDUCATIVA
}

\author{
EMOTIONAL EDUCATION IN \\ INTEGRATION KEY. A CONTRIBUTION TO \\ EDUCATIONAL INNOVATION
}

María Elena Huerta Rivero

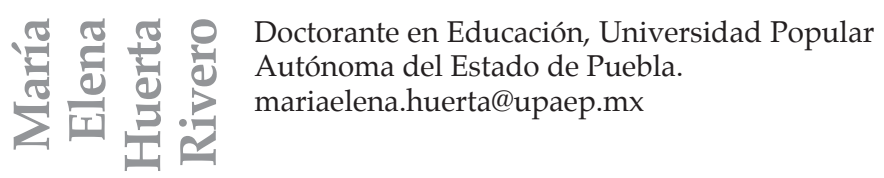

\section{RESUMEN}

En el presente trabajo se describe la necesidad de adaptación de la educación al cambio, en este panorama postmoderno, pues la educación tradicionalmente ha desatendido la dimensión emocional del ser humano. Por ello, se hace una breve descripción, análisis y contraste de los dos enfoques de educación emocional: en clave de regulación y en clave de integración. Posteriormente, se hace una reflexión sobre la educación personalizante y las necesidades concretas de innovación educativa en el actual contexto mexicano. Finalmente, se hace una propuesta desde el enfoque de educación emocional en clave de integración, para el contexto mexicano. 
Palabras clave: educación emocional, regulación emocional, integración personal, innovación educativa.

\begin{abstract}
In this paper we describe the need to adapt education to change, in this postmodern panorama. In which, education traditionally has neglected the emotional dimension of the human being. Therefore, a brief description, analysis and contrast of the two approaches to emotional education are made: in the key of regulation and in the key of integration. Subsequently, a reflection of personalized education and on the specific needs of educational innovation in the current Mexican context is made. Finally, a proposal is made from the focus of emotional education in the key of integration for the Mexican context.
\end{abstract}

Key words: emotional education, emotional regulation, personal integration, educational innovation.

\title{
INTRODUCCIÓN
}

El mundo postmoderno se caracteriza por cambios rápidos y drásticos que reclaman capacidad de adaptación y que lo vuelven muy competitivo. Este escenario impacta también al ámbito de la educación como de la innovación educativa.

Al tocar el tema de la educación desde sus diversas y complejas aristas, aparece a lo largo de la historia una deuda; la educación se reduce al tratamiento de los procesos de enseñanza, aprendizaje y evaluación de los conocimientos, saberes, actitudes, valores o competencias, desde un enfoque cognitivo.

Más, de acuerdo con López Calva en su artículo Hacia dónde va el corazón (2002), al caminar por los pasillos de cualquier universidad, es común toparse con la dolorosa experiencia de mirar salones repletos de estudiantes aburridos, mientras el maestro se desarma por captar su atención. 
Así las cosas, resulta pertinente preguntarse: ¿Cómo aprenden los estudiantes? Esta interrogante plantea un cambio de mirada, un giro drástico en la educación, pues pasa de un proceso centrado en la enseñanza a un proceso centrado en el aprendizaje.

Mucho se ha teorizado sobre el tema desde Rosseau hasta Vigotsky y su constructivismo. Sin embargo, la pregunta sigue ahí: ¿Cómo aprende el estudiante a conocer, a hacer, a ser y a convivir? (Delors, 1996).

Es claro que el conocimiento lo construye el alumno a través de procesos cognitivos internos, de su relación con los demás y de la realidad que lo rodea. La experiencia en las aulas confirma que el estudiante aprende si la propuesta académica del maestro converge en algún punto con los anhelos de su corazón, facilitando la actualización de las potencialidades del joven, guiadas por sus exigencias de autenticidad. Poco se habla de metas que tengan que ver con el crecimiento de la persona y casi nada se toma en cuenta sobre su dimensión afectiva, la cual es una dimensión constitutiva.

Por tanto, parece conveniente preguntarse: ¿Qué papel juega la educación emocional en el ámbito escolar? ¿Cuáles son los diferentes enfoques de la educación emocional? ¿Cuáles sus principales aportes? ¿Se puede hablar de la educación emocional en clave de integración, como un elemento innovador en el contexto de la educación mexicana?

Estas interrogantes tratarán de ser contestadas a lo largo del presente trabajo.

\section{LA IMPORTANCIA DE LA EDUCACIÓN EMOCIONAL}

Pescador (2005) afirma que los modos de enseñanza, aprendizaje y evaluación no deben centrarse sólo en metas académicas, es necesario prestar atención al mundo emocional, que afecta sobremanera los procesos y espacios educativos.

Así las cosas, García Retana (2012) argumenta que actualmente se promueve una dura batalla por cambiar el carácter «anti-emocional» 
del tipo de escuela que dominó hasta finales del siglo $\mathrm{XX}$, en el cual los afectos fueron formalmente anulados con el objetivo de ordenar el tiempo, la mente, el cuerpo y, más aún, las emociones de los estudiantes. Justificando que entre la razón y la emoción había una distancia abismal (Casassus, 2006, citado por García, 2012), estableciéndolas como polos antagónicos de la vida humana. Por tanto, la escuela anti-emocional postuló una clara diferencia entre el pensamiento racional y emocional, caracterizando al primero como «objetivo» y dando al segundo un carácter «subjetivo». Esto debido a que el raciocinio ha sido unido históricamente con la lógica y especialmente con las matemáticas, por el legado de la cultura griega al mundo occidental, la cual favoreció las estructuras mentales donde la lógica aristotélica se identificó con el razonamiento correcto. Opuesto a esto, se ha considerado que el pensamiento emocional y la consiguiente conducta emocional, acarrean a una conducta desorientada.

En contraste con lo anterior, la Secretaría de Educación Pública (SEP) presenta el Nuevo Modelo Educativo (2017) como una propuesta que parte de analizar las exigencias y necesidades sociales.

Por ende, el nuevo Modelo Educativo incluye, en primer lugar, la colaboración entre el gobierno federal y los gobiernos estatales; pero también la relación entre la autoridad educativa y el magisterio. Asimismo, el Modelo Educativo reconoce la importancia del papel que desempeña el Instituto Nacional para la Evaluación de la Educación (INEE), el Poder Legislativo, los padres de familia y otros actores de la sociedad civil.

Uno de los elementos novedosos del nuevo modelo es la atención a lo emocional y ahí aparece lo siguiente:

Incorporación del desarrollo de habilidades socio-emocionales al currículo. Reconocimiento del papel central de las habilidades socio-emocionales en el aprendizaje de niñas, niños y jóvenes, así como de la capacidad de las personas para relacionarse y desarrollarse como seres sanos, creativos y productivos (SEP, 2017, p. 54). 
Es la primera vez en la Historia de la Educación en México que se pone tanto énfasis en las habilidades socio-emocionales de los niños y jóvenes, porque ya se detectó la necesidad de ello.

Sin embargo, la educación emocional es un tema que durante muchos años ha pasado a segundo plano, probablemente por influencia de la modernidad que hizo de la Razón una Diosa y que, muchas veces, despreció el papel de las emociones y los sentimientos. Resulta paradójico, porque durante muchos años los filósofos fueron los principales educadores de las emociones. Podemos citar a Sócrates y su preocupación por el amor que tan sabiamente plasmó Platón (citado por Francisco, 1979) en El banquete, ya que afirmó que cuando el amor se dedica al bien y se adapta a la templanza y a la justicia, nos procura una felicidad perfecta. Aristóteles (2003) con su Ética a Nicómaco, examinó el vínculo del carácter y la inteligencia con la felicidad, además ser considerada una de las principales obras en la que se basa la ética occidental. Epicuro desarrolló una filosofía para la vida feliz, que sólo en parte llega a nosotros, gracias a Diógenes Laercio. Séneca con su libro, De la felicidad, propuso seguir las reglas de la naturaleza para ser virtuosos. El mismo Descartes (1989) considerado padre de la Modernidad, en su Tratado de las pasiones, su última obra escrita profundizó, e inclusive rectificó, algunas de las tesis sostenidas con anterioridad. Posteriormente, C.S. Lewis (2016) afirmó en La abolición del hombre que, sin la ayuda del entrenamiento de las emociones, el intelecto carece de poder frente al organismo animal.

En el mismo tenor, Pescador (2005), señaló que los orígenes del estudio de la inteligencia emocional se remiten a los trabajos de Edward Thorndike, quien conceptualizó a la inteligencia social «como la habilidad para comprender y dirigir a los hombres y a las mujeres [...], y para actuar sabiamente en las relaciones humanas».

En el año 1920, Thorndike divulgó un artículo denominado La inteligencia y sus usos dando un paso adelante en la comprensión de la inteligencia al resaltar su aspecto social. En el artículo mencionado, el autor señaló tres tipos de inteligencia: abstracta, mecánica y social. Por «inteligencia abstracta» comprende Thorndike la capacidad para emplear 
símbolos como: palabras, números, fórmulas físicas y químicas, leyes, decisiones legales, etcétera; por «inteligencia mecánica», la capacidad para comprender y emplear objetos tales como armas y barcos; y, finalmente, por «inteligencia social», la capacidad de comprender y conducir a hombres y mujeres, en otros términos, de proceder sabiamente en las relaciones interpersonales.

Al correr del tiempo, Howard Gardner en 1983 propuso en Frames of mind, la teoría de las «inteligencias múltiples»; en ellas se introducen la inteligencia intrapersonal y la interpersonal, que son dimensiones de la inteligencia emocional, ya que las dos definen la habilidad de dirigir de manera apropiada la vida personal, en cuanto al orientar las relaciones con uno mismo y con los demás.

Vale la pena destacar que propiamente el tema de «inteligencia emocional» fue incluido en 1990 por Peter Salovey y John D. Mayer. Ambos la explicaron como una habilidad para percibir, asimilar, comprender y regular las propias emociones y las de los demás, promoviendo un crecimiento emocional e intelectual, en su libro ¿Qué es la inteligencia emocional?, escrito en 1997.

Así, el término de «inteligencia emocional» fue implementado por Salovey y Mayer en el año 1990, y llamado por estos autores como una variante de «inteligencia social», que incluye la capacidad de manejar nuestras propias emociones y las de los demás, así como de distinguir entre ellas y emplear la información que nos generan para orientar nuestro pensamiento y acciones. Dicho de otra mane$\mathrm{ra}$, se refiere a la facilidad de una persona para entender sus propias emociones y las de los otros, y comunicarlas de manera que sean provechosas para sí mismo y la cultura que lo adopta. Para ambos psicólogos, la inteligencia emocional implica el análisis verbal y no verbal, la manifestación emocional, la regulación de la emoción en uno mismo y en los otros, y la aplicación del tema emocional en la solución de problemas.

Ambos autores toman, en 1990, las inteligencias personales que Gardner estableciera desde 1983 en su descripción básica de inteligencia emocional, ampliándolas en cinco categorías principales: 
1) Conocer las propias emociones. Para los estudiosos que están actualmente investigando en el ámbito de la inteligencia emocional, el autoconocimiento es la clave de la inteligencia emocional. El identificar nuestras emociones nos posibilita un mayor dominio y dirección en nuestras vidas; por el contrario, la falta de habilidad para identificarlas nos deja en sus manos.

2) El manejo de las emociones. La inteligencia emocional no se basa sólo en el conocimiento de nuestras emociones: también es importante la habilidad de dirigirlas de forma adecuada, esquivando los sentimientos duraderos de ansiedad, irascibilidad, etcétera.

3) El motivarse a uno mismo. La habilidad de automotivarse, es decir, de regular las emociones enfocadas a un objetivo es indispensable para poner atención, superar un obstáculo y para el fomento de la creatividad.

4) El reconocer las emociones en los demás. La empatía es la capacidad relacional más destacada, ya que implica el principio del altruismo y abarca la facilidad de compenetrarse con los anhelos y las necesidades de los otros.

5) La capacidad de relacionarse con los demás. Habla de la habilidad para la aptitud social, que en gran parte se refiere a la regulación de las emociones de las personas con las que se convive.

El filósofo Daniel Goleman planteó esta noción en su obra La inteligencia emocional (1995). Ahí afirma que la inteligencia emocional está constituida por: autoconocimiento emocional (conciencia de uno mismo), autocontrol emocional (autorregulación), automotivación, reconocimiento de emociones ajenas (empatía) y habilidades sociales para las relaciones interpersonales.

Ante la complejidad del tema, han surgido dos propuestas muy distintas de educación emocional, de acuerdo con Orón (2017): una en clave de regulación y la otra en clave de integración. 


\section{EL ENFOQUE DE LA EDUCACIÓN EMOCIONAL EN CLAVE DE AUTORREGULACIÓN}

La primera propuesta sobre educación emocional surge como un enfoque de autorregulación: comprender las emociones; distinguir las emociones positivas de las nocivas; fomentar las primeras y reprimir las segundas, tendiendo así a la regulación.

Aparece como representante destacado de esta corriente, el doctor español Rafael Bisquerra Alzina. El autor establece su propuesta partiendo del siguiente concepto sobre lo que es una emoción:

[...] un estado complejo del organismo caracterizado por una excitación o perturbación que predispone a una respuesta organizada. Las emociones se generan como respuesta a un acontecimiento externo o interno (Bisquerra, 2003, p. 12).

El proceso de una vivencia emocional lo esquematiza con la siguiente figura:

Figura 1. Esquema del concepto de emoción.

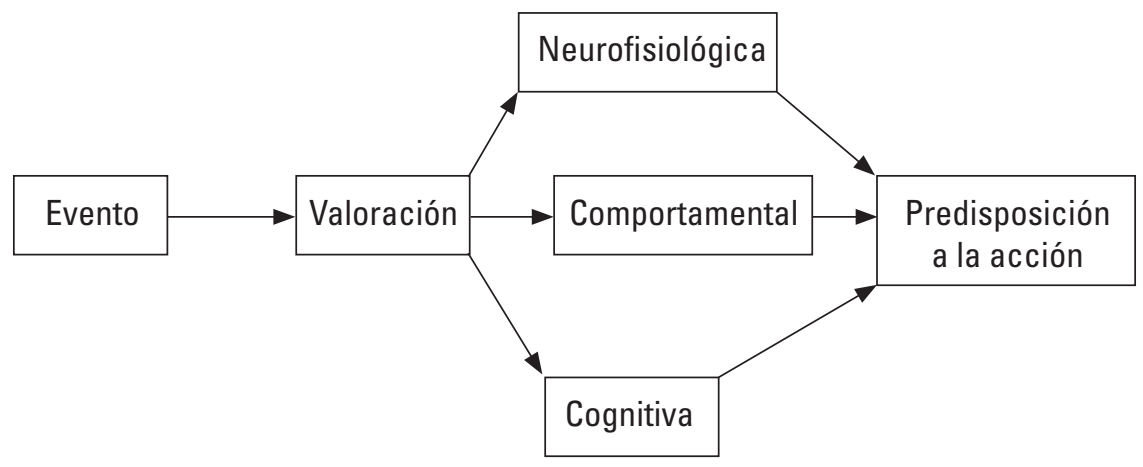

Fuente: Rafael Bisquerra, 2003, p.12. 
Siguiendo al autor, existen tres componentes de una emoción: neurofisiológico, conductual y cognitivo. El neurofisiológico se expresa por medio de fenómenos como: hipertensión, sudoración, sequedad en la boca, cambios en los neurotransmisores, etcétera. Todas ellas son respuestas involuntarias, que no se pueden controlar. El componente conductual, se manifiesta mediante expresiones de las personas, y a través de ellas, se puede inferir cuáles experimenta. El componente cognitivo, también llamado «vivencia subjetiva», es el sentimiento: angustia, miedo o rabia, y permite calificar a un estado emocional y denominarlo con un nombre.

De acuerdo con Bisquerra, la «educación emocional» es una novedad educativa que se justifica debido a algunas carencias sociales reconocidas en la actualidad. La meta principal de esta educación es el desarrollo de competencias emocionales que favorezcan el bienestar personal y social.

El autor define la educación emocional como:

[un] proceso educativo, continuo y permanente, que pretende potenciar el desarrollo de las competencias emocionales como elemento esencial del desarrollo integral de la persona, con objeto de capacitarle para la vida. Todo ello tiene como finalidad aumentar el bienestar personal y social (2003, p. 21).

Aparece entonces la educación emocional como un proceso, que deberá ser permanente y constante en el currículo dentro de la academia y también a lo largo de toda la vida, ya que la educación trasciende a lo escolar. Por ello, para Bisquerra la educación emocional se coordina con el espectro y fines de la orientación psicopedagógica.

Por otro lado, surge otro paradigma sobre la educación emocional con un enfoque de integración, encabezado por el doctor José Víctor Orón Semper. 


\section{EL ENFOQUE DE LA EDUCACIÓN EMOCIONAL EN CLAVE DE INTEGRACIÓN}

Su enfoque al respecto de la educación emocional, es ante todo un enfoque interdisciplinar entre la filosofía, la neurociencia, la psicología y las ciencias de la educación. Aquí radica su primera novedad.

La propuesta de educación emocional de José Víctor Orón se expande en dos movimientos: el primero recorre una vía para conocer la información presente en la realidad emocional; y el segundo, se enfoca en el carácter de tendencia de la emoción, y sugiere que el joven ejecute actos globales personales que lo dirijan a encarar la siguiente pregunta: ¿Quién quiero ser? (Orón, 2017, p. 3).

El autor califica a la emoción como un fenómeno de carácter personal, por ello hay que abordarle desde una aproximación interdisciplinar entre la neurociencia, la filosofía y la psicología (2017, p. 20).

Por eso, como tema de investigación, es importante el comprender la emoción en relación con toda la persona y no simplemente prestando atención a su comportamiento posterior y lo agradable o desagradable de la experiencia. Ésta es una de las diferencias significativas con el enfoque regulador de Bisquerra: se toma en cuenta a la persona como un ser en su integralidad.

Por otro lado, el autor reconoce que el hito de la inteligencia emocional ha servido de punto de partida para el desarrollo de la educación emocional, sobre todo al ser relacionada - a partir de Goleman-con una palabra pasada de moda: carácter.

El autor destaca como punto importante el aporte de Mayer y Salovey sobre la definición del término Inteligencia Emocional, en 1990. A partir de ahí se da un impulso grande a la educación emocional, desde la propuesta regulatoria.

Menciona que desde entonces se desarrollan diversos manuales recopilatorios de la propuesta regulatoria. Son grandes colecciones con participación de diversos autores provenientes de las corrientes psicológicas y que se acercan de manera creciente a la neuropsicología. Por 
lo que prevalece el enfoque regulatorio, el que de acuerdo con Orón intenta actuar sobre las emociones para cambiarlas, o modificar sus consecuencias.

Lo que aquí se debate es si el sentido de la intervención es la experiencia hedónica de la persona o el logro de sus objetivos. Si se trata de apostar por el valor hedónico, la pauta es clara: propiciar lo agradable y disminuir lo desagradable. Más cuando el objetivo de la intervención busque el alcance de las metas, el impulso o la reducción de los sentimientos, dependerá de las metas marcadas. Entonces, la intervención está orientada a la modificación (Orón, 2017, p. 31).

Por ende, este enfoque regulatorio de Bisquerra se asume, en el ámbito educativo, como una valiosa estrategia ya que se asocia al éxito académico, pues favorece en el alumno una serie de elementos: establecimiento de metas, interés, recursos cognitivos y meta-cognitivos, motivación, aprendizaje y logro académico (2017, p. 34).

En cambio, la hipótesis fundamental de Orón respecto de la educación emocional es la siguiente:

La autogestión emocional del adolescente es el conjunto de acciones tendientes a la integración de la emoción en la globalidad de la persona, que permite la actualización de la identidad, la socialización y la maduración de las funciones ejecutivas para que el joven pueda hacer actos globales-personales (p. 35).

Si en lugar de formular esta hipótesis como el camino que recorre el joven (autogestión emocional), la formulamos en los términos de la actividad educativa del adulto (educación emocional), quedaría de la siguiente forma: la educación emocional consta en favorecer que el estudiante asuma su situación emocional como un comienzo para el crecimiento personal dentro de un contexto de la integración personal (p. 35). Por eso, para Orón, la educación emocional no nace en las emociones, es más bien una educación de la persona, no de las emociones.

La palabra autogestión emocional influye en dos ángulos: a) que la educación debe ser del adolescente completo, más que de sólo la 
emoción; y, b) que debe ayudársele al joven a encontrar el sentido de su vida, más que dirigirlo a una determinada dirección.

Por ende, es más acertado señalar que quien se educa es la persona en su totalidad y en su complejidad, ya que la educación emocional se sustenta en las vivencias concretas de la persona. En este contexto, una palabra destacada es la de «ayuda» pues, de acuerdo con Orón, se educa favoreciendo el crecimiento del joven. Esta visión se centra menos en competencias y habilidades, y más en el adolescente. En cuanto a la emoción como un efecto y tendencia en la persona, Orón afirma que la gestión emocional se propone como punto de arranque de la integración, buscando un impacto global en la persona. Por tanto, la hipótesis habla del papel de la emoción en la globalidad de la persona.

En el presente trabajo enfatizamos dos aspectos de la emoción: como efecto y como tendencia. Orón señala que las emociones son precedentes de los actos y también consecuentes. La realidad emocional, al ser compleja, puede contemplarse desde dos puntos de vista: la precedencia de la emoción es tendencia y también es efecto al ser consecuencia de los actos.

En las dos situaciones, la emoción supera el hecho de sentir algo agradable o desagradable, ya que alude a la totalidad de la persona. Por tanto, en cuanto efecto, la emoción será un conducto para el autoconocimiento personal. Y como tendencia, la emoción moverá a la persona manifestándose como deseo, la que necesitará del acto global personal para propiciar su crecimiento.

Así las cosas, se necesita hacer referencia a la globalidad de la persona para entender las dos dimensiones de la emoción, ya que sirve para el autoconocimiento personal o para el crecimiento personal. Sin olvidar que las personas viven diferentes experiencias $y$, por ende, un conjunto de múltiples causas generan como efecto las emociones.

En cuanto efecto, las emociones deben considerarse como información. En nivel secundario, las emociones suscitan tendencia. Por ello, para la integración de las tendencias se requiere del acto globalpersonal, lo que pide relacionar hábito, virtud y crecimiento (2017, p. 37). 
Para ser precisos, la gestión emocional no existe, más bien lo que se da es el autodominio. Vale la pena aclarar que el florecimiento de una sola dimensión humana no es posible y no nos llevaría al crecimiento personal, sino a la deformidad.

Lo deseable es que el adolescente crezca, se haga cargo de su vida y sea depositario de originalidad, por lo particular de su vida personal en la sociedad. Entonces, como sucede en todas las estructuras, cuando un componente crece, lo demás también lo hace (p. 41).

En conclusión, el adolescente requiere de la gestión emocional (autodominio) para propiciar la reconsideración de circunstancias inesperadas, para la toma de decisiones diarias y difíciles. La idea clave aquí es que el joven apueste y actúe para su desarrollo personal. Pero lo primordial es que esta habilidad es educable, por tanto, no está vinculada necesariamente a la circunstancia familiar, capacidad intelectual o personalidad.

Por el contrario, Orón afirma — siguiendo a Dweck- que la cosmovisión del joven es una alternativa educable, decisiva y de mucha influencia para la gestión emocional. Por ende, el joven se convierte en protagonista de su vida, gracias a una adecuada intervención educativa (2017, p. 42).

Ahora ¿qué aporta, a la innovación educativa, el contraste de estos dos enfoques de educación emocional?

De acuerdo con Margalef y Arenas (2006), la noción de innovación según Zaltman y otros (1973), alude a tres nociones relacionadas entre sí. Innovación como invención, proceso creativo por el cual dos o más nociones o entidades existentes son mezcladas en forma novedosa, generando algo nuevo. Proceso por el cual una innovación existente se vuelve parte del repertorio cognitivo y comportamental de una persona. Una innovación también puede ser una idea, una conducta o cosa que es visto como novedad.

Así las cosas, la novedad de la propuesta de Orón es el enfoque de integración. Para el autor, la palabra «integrar» es medular para esta investigación. En esta investigación, la manera en la que se entiende esta 
palabra es lo que permitirá la interdisciplinaridad. Entonces, la palabra integrar funcionará de vínculo entre las diferentes ciencias. Orón caracteriza integrar como «una dinámica en la que los diversos aspectos y relaciones se van diferenciando y optimizando en la medida en que se ponen, a su vez, en relación entre sí» (2017, p. 50).

Así conceptualizada, la noción de integrar puede aplicarse a procesos cerebrales, a procesos psicológicos o a procesos personales. Vale la pena aclarar que cuando se habla de personas es importante sustituir la palabra «dinámica» por «maduración». Ya que la integración es la dinámica que aclara cómo se da el crecimiento o el florecer humano. Aún más: la integración es la dinámica que detalla el desarrollo y el desempeño de las estructuras abiertas. Por consiguiente, al hablar de personas, la noción de integrar comporta una maduración en la que los diversos aspectos y relaciones se van diferenciando y optimizando en la medida en que se sitúan, a su vez, en relación entre sí.

Por el contrario, el pensamiento modular — sustentado por Bisquerra-, afirma que las realidades surgen por separado y luego se vinculan. Desde la neurociencia, esto es igual a decir que los diferentes sentidos (gusto, tacto, oído...) y las dimensiones emocionales (cognitivas o sociales) se estructuran con autonomía, pues cada una tiene su módulo propio. Por tanto, la integración aparece después de la formación.

De la misma manera, planteado desde la psicología se propone que es muy distinto el crecimiento moral, del cognitivo y del emocional, ya que una vez constituidos, cada uno en su etapa correspondiente, se integrarán. En cambio, la perspectiva que irriga la propuesta de sistemas dinámicos complejos (en neurociencia), sistémica (en filosofía) y global (en psicología) afirma que los diversos aspectos coexisten en un nudo de interrelaciones desde el origen, y si la integración entre todos no es lograda, ninguno de ellos existe (Orón, 2017, p. 51).

Esta distinción es esencial, más aún cuando la palabra integración es utilizada en el modelo regulatorio y en el modelo de integración. Por ello es conveniente precisar, que en el modelo regulatorio, la integración es comprendida como adjetivo (integrado) o sustantivo (integración), mientras que, en el modelo propuesto, la integración es 
entendida como verbo (integrar). El verbo (integrar) puede incluir al adjetivo (integrado) o al sustantivo (integración), pero no al revés. De acuerdo con el autor:

En el modelo regulatorio, la acción es regular y la integración, el efecto. En el modelo integrador la acción es integrar y el crecimiento, el efecto. Por eso en el modelo regulatorio la integración se entiende sobre todo como adjetivo y sinónimo de coherencia interna, es un proceso de cierre, mientras que en el modelo integrador la integración comporta una mayor apertura (2017, p. 52).

Se propone que este movimiento es lo decisivo del ser. Es decir, lo esencial de las cosas surge gracias a una realidad dinámica, y por tanto cada ser se identificará con su propia dinámica. La manera de caminar de lo relacionado a lo integrado será propia de cada realidad; ésa es su dinámica distintiva. La dinámica es característica del ser; siempre perdura, aunque eso no impide que se haya lesionado en experiencias pasadas. En la dinámica de la integración pueden distinguirse una serie de contrarios, como la novedad y continuidad, o unidad y diversidad, que respectivamente se tironean.

La unidad nace por la participación de la misma dinámica no por la igualdad. «Unidad» es una palabra complicada, ya que aparenta que detiene el crecimiento. Desde este enfoque, se habla más bien de identidad personal que nunca es cerrada, más que de unidad personal (p. 53).

En esta perspectiva, si no hay intervención activa de los elementos no existe integración. No hay un elemento que domine al otro, sino que la dinámica integradora avala que el carácter activo y pasivo de los elementos se dé al mismo tiempo en las dos partes. Las dos son agentes de cambio, los dos cambian. El acto de integrar puede representarse por el binomio dar/recibir ya que su dinámica nunca se cierra: para recibir alguien debe dar y para dar alguien tiene que recibir. Así las cosas, para que las partes consideradas se integren, tienen que dar y recibir lo propio y, así, se enriquecen de manera recíproca; por tanto, crecen. Vale la pena precisar que, si uno da, no sólo posibilita que el otro reciba, sino que favorece que el otro dé, elaborando lo recibido. Sino acogiera, no proporcionaría lo que da. 
Esto origina una dinámica siempre abierta. Sin embargo, en esa dinámica abierta existen las alternativas de enriquecimiento o empobrecimiento (Orón, 2017, p. 54).

Se concluye que la integración es mirada de manera muy distinta en la visión modular ostentada por Bisquerra, pues sucede al final, como suma de los elementos; es así como surge la integración. En cambio, en la visión sistémica presentada en el enfoque de Orón, integrar es la manera de ser y crecer del sistema, y el sistema es la persona relacionándose con los otros en un contexto particular. Aquí radica la principal novedad de la educación emocional en clave de integración.

\section{INNOVACIÓN EDUCATIVA EN EL CONTEXTO DEL MÉXICO ACTUAL}

En el contexto mexicano, uno de los ámbitos en que se manifiesta la necesidad de innovación educativa es en el perfil del docente.

De acuerdo con la Ley General del Servicio Profesional Docente, existe la exigencia de afirmar un ejercicio docente que robustezca la cualidad y la imparcialidad de la educación básica y media superior.

En el mismo documento, más adelante se expresan, entre otros propósitos de ésta:

- Garantizar una altura idónea de desempeño de los docentes, directivos y supervisores.

- Asegurar la educación, formación, y actualización constante a partir de leyes, propuestas y acciones concretas (SEP, 2015, p. 11).

Por todo lo anterior, es relevante revisar las dimensiones del docente que se presentan en el siguiente cuadro: 


\section{Figura 2. Rasgos del perfil profesional del docente.}

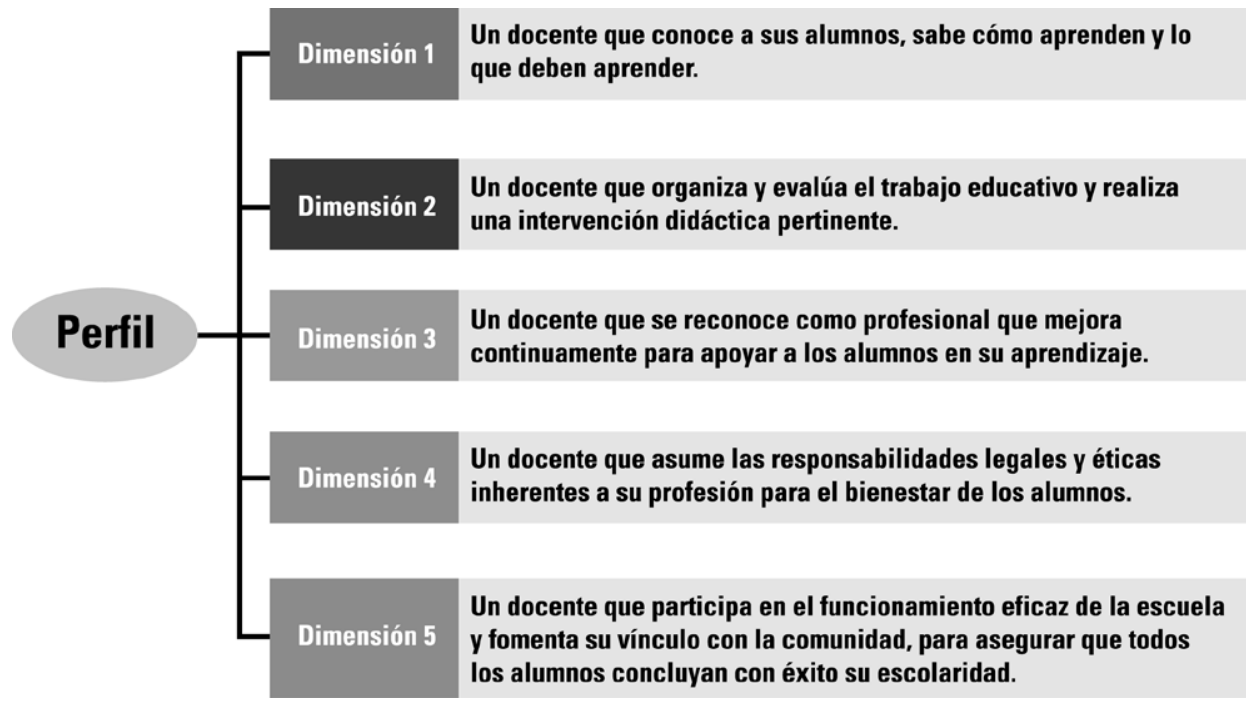

Fuente: SEP, 2015, p. 12.

Como afirma López Calva en su artículo Vivir en el pantano, un ensayo contra la educación en valores, una educación personalizante parte de reconocer la complejidad del ser humano. Maestro y estudiante ponen de su parte para guiar cabalmente este «irrestricto deseo de conocer y elegir el bien», favoreciendo condiciones, actividades y procesos para que el sujeto sea cada vez más atento, inteligente, razonable y responsable, y cada vez más hábil para descubrir su propio dinamismo (2015, p. 15).

Si estas dimensiones se ubican dentro del contexto actual, propuesto por el Modelo Educativo 2017 desde la misma SEP, en el cual se plantea la necesidad fundamental de robustecer las habilidades 
socio-emocionales que favorezcan que los estudiantes sean felices, autodeterminados, constantes y resilientes — es decir que puedan asumir y sobrellevar nuevas situaciones con creatividad (SEP, 2017, p. 63) -, se cae en la cuenta de la necesidad de formar a los profesores en esta dimensión de la educación emocional.

De acuerdo con López Calva, la educación personalizante necesita trabajar arduamente con el ámbito emocional del sujeto, ya que las emociones influyen en todos los otros ámbitos del ser humano. Pues, aun después de llegar a un juicio de valor, los sentimientos pueden orientar a la persona a actuar en contra de ese juicio (2015, p. 19).

Por eso se trata de volver las emociones, más inteligentes, razonables y responsables, para contribuir a un proceso más auténtico de autoconstrucción personal.

Esto queda enfáticamente descrito en el mismo modelo en el siguiente cuadro:

\section{Figura 3. Habilidades socio-emocionales descritas en el Nuevo Modelo Educativo}

Las habilidades socio-emocionales son comportamientos, actitudes y rasgos de la personalidad que contribuyen al desarrollo de una persona. Con ellas pueden:

- Conocerse y comprenderse a sí mismas.

- Cultivar la atención.

- Tener sentido de autoeficacia y confianza en las capacidades personales.

- Entender y regular sus emociones.

- Establecer y alcanzar metas positivas.

- Sentir y mostrar empatía hacia los demás.

- Establecer y mantener relaciones positivas.

- Establecer relaciones interpersonales armónicas.

- Tomar decisiones responsables.

- Desarrollar sentido de comunidad. 
Tradicionalmente, la escuela ha fijado la atención en el desarrollo de las habilidades intelectuales y motrices de los niños y jóvenes, sin prestar el mismo interés por las emociones. Se pensaba que esta área correspondía más al ámbito familiar que al escolar o que era parte del carácter de cada persona. Sin embargo, cada vez hay más evidencias que señalan el papel central de las emociones en el aprendizaje, así como en la capacidad de los individuos para relacionarse y desenvolverse como seres sanos y productivos. Las habilidades socio-emocionales son fundamentales para el desarrollo de las personas, porque se asocian con trayectorias escolares, personales y laborales más exitosas y con mayor aprendizaje.

En el Modelo Educativo se incorpora el desarrollo de las habilidades socio-emocionales como parte del currículo, tanto en la educación básica, dentro del componente curricular "Desarrollo personal y social", como en la educación media superior, al incluirlas en el Marco Curricular (MCC).

Fuente: SEP, 2017, p. 75.

Así las cosas, la importancia de la educación emocional, se plasma curricularmente en el mismo modelo, como se muestra en la gráfica siguiente: 
Figura 4. Componentes curriculares de la Educación Básica

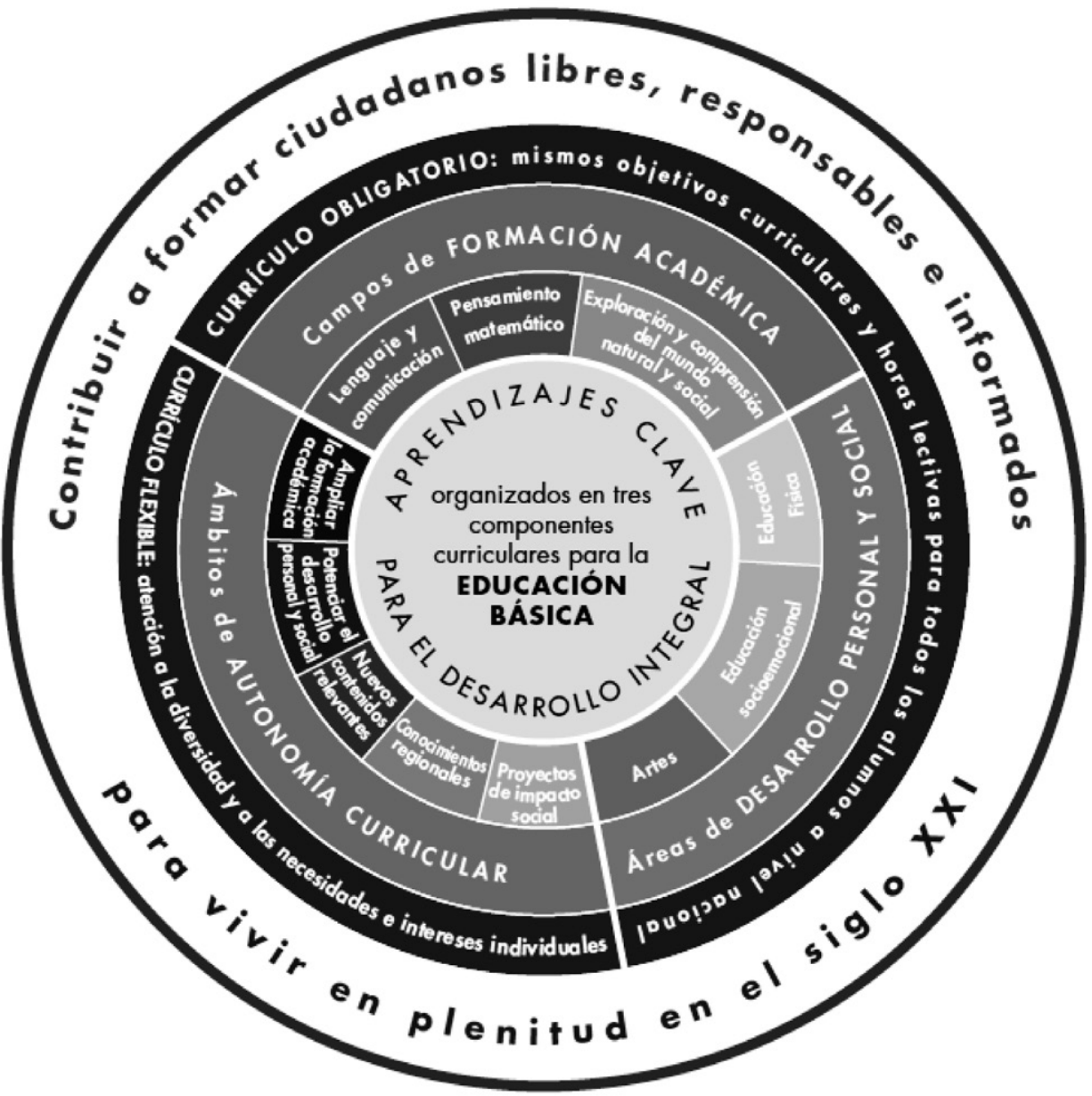

Fuente: SEP, 2017, p. 73. 
Según López Calva, el crecimiento de la persona depende de intentar integrar todas estas fuerzas que surgen en la persona, llevándola a diferentes sensaciones, interrogantes, explicaciones, juicios, valoraciones, deliberaciones y alternativas de acción (2015, p. 17).

La educación personalizante es una tarea facilitadora del proceso introspectivo y de autoconocimiento que permite el desarrollo de cada sujeto, en una exploración libre y responsable de integración de su propia autoconstrucción y a través de sus propias contradicciones (p. 18). Así, la educación personalizante, plantea las posibles relaciones entre la formación valoral y la educación emocional, percibiendo la integralidad de la persona.

Por todo lo anterior, queda planteada la necesidad de innovar educativamente en la formación de los docentes que trabajarán la dimensión socio-emocional con sus estudiantes, la cual, previamente, no se atendía de manera primordial. Por ello, si las habilidades socio-emocionales son relevantes en el modelo educativo, los profesores deberán prepararse en esta dimensión. Se ha elegido el enfoque de educación emocional en clave de integración de Orón, como modelo de innovación educativa, porque está en sintonía con una visión holística del ser humano, la que pudiese servir a los propósitos formativos del Nuevo Modelo Educativo.

\section{POSIBLES APORTES DE LA EDUCACIÓN EMOCIONAL EN CLAVE DE INTEGRACIÓN PARA LA FORMACIÓN DOCENTE}

De acuerdo con Orón (2018), la innovación requiere de una disposición psicológica personal. Por tanto, se necesita de una confianza básica interpersonal: que uno quiera ir donde está el otro. Así las cosas, la novedad surge en el deseo de encontrarse con otro, por ende, el reto de la innovación educativa consiste en reconocer que un desafío para un ser humano es otro ser humano. 
Entonces, la significatividad de la educación surge en las relaciones interpersonales, no como simples moduladores, sino como generadores de significado. Porque el mundo no es un reto, el desafío es encontrarse con otra persona. Aquí radica la principal diferencia con la propuesta en clave de regulación de Bisquerra, pues para este autor -como hemos indicado- las emociones deberán cambiarse favoreciendo lo agradable y disminuyendo lo desagradable, para que la persona logre sus objetivos; mas eso, es educar para resolver problemas, mientras que Orón apuesta por educar ayudando a crecer. Eso implica que el maestro favorezca en sus estudiantes la introspección y el autoconocimiento, con la finalidad de que el joven observe que sus emociones le ofrecen un panorama vital diferente ante el que puede y debe posicionarse. Al reconocer esta necesidad, surge la posibilidad de crecer.

Así, la educación debe enfocarse en el crecimiento de la relación interpersonal —entre el maestro y el alumno-, porque lo que mueve a una persona es otra persona. Por todo esto, la verdadera innovación consistirá en facilitar, mediante estrategias creativas, el encuentro entre el docente y los estudiantes de cualquier nivel. He aquí el desafío para la educación y sus actores, una innovación profunda basada en la novedad de la persona.

La educación emocional, en clave de integración, supone tomar en cuenta que todo existe en un tejido de relaciones e interacciones, por lo que el mejor soporte educativo es la relación docente-dicente. Preparar al maestro para cuidar la relación con sus estudiantes es un aporte concreto a un ámbito educativo mexicano muy complejo.

Se concluye que la educación humana debe ser holística. La vida exige iniciar ratificando la unidad, grandeza y complejidad del ser humano; cerciorarse que, en el trayecto educativo, esa grandeza y complejidad estén presentes todo el tiempo (Orón, 2018, p. 87) puesto que, dentro de esta visión holística, la dimensión emocional es muy importante. Aquí reside la principal innovación de la propuesta de Orón, a la educación emocional. 


\section{REFERENCIAS}

Aristóteles. (2003). Ética a Nicómaco. El Cid Editor.

Bisquerra, R. (2003). Educación emocional y competencias básicas para la vida. Revista de Investigación Educativa, 21(1), 7-43. Recuperado en Junio de 2017 de http://revistas.um.es/rie/ article/view /\%2B99071

Bisquerra, R. (2011). Educación emocional. Propuestas para educadores y familias. Bilbao: Desclée de Brower.

Delors, J. (1996) de la publicación: La Educación Encierra un Tesoro (Libro). Santillana. UNESCO. Cap, 4, 91-103.

Descartes, R. (1989). Tratado de las pasiones del alma. Barcelona: Planeta-De Agostini.

García-Retana, J.A. (2012). La educación emocional, su importancia en el proceso de aprendizaje. Educación, 36, 1-24. Recuperado en Diciembre de 2016 de http://www.redalyc.org/articulo. oa?id=44023984007

Gardner, H. (2011). Frames of mind: The theory of multiple intelligences. Hachette UK

Goleman, D. (1995). Inteligencia emocional. Editorial Kairós.

Orón, J. (2017). La integración emocional en el desarrollo del adolescente. Aportaciones de la neuropsicología y la filosofía de Leonardo Polo. Tesis Doctoral. Universidad de Navarra, España.

Orón, J. (2018). ¿Qué es la innovación educativa? Conferencia magistral. UPAEP.

Orón, J. (2018). Educación y persona. Reflexiones críticas sobre el sentido de la Educación. $1^{a}$ Edición. UPAEP-Tirant Humanidades, México. 
Pescador, J.E.P. (2005). Presentación de la reedición del número 54 de la RIFOP (volumen 19, 3; diciembre de 2005) La Educación Emocional, una revolución pendiente. Revista Electrónica Interuniversitaria de Formación del Profesorado, 19(3), 9-13.

Francisco, L. (1979). Diálogos de Platón. Editorial Porrúa. Colección Sepan Cuantos. XVIII Edición, México.

Lewis, C. S. (2016). La abolición del hombre. HarperCollins Español.

López-Calva, J. M. (2002) Hacia dónde va el corazón. Revista DIDAC Número: 39, pp 5-11. México.

López-Calva, J. M. (2015). Vivir en el pantano, un ensayo contra la educación en valores. Revista Magistralis 14.

Margalef García, L. y Arenas Martija, A. (2006). ¿Qué entendemos por innovación educativa? A propósito del desarrollo curricular. Perspectiva educacional, formación de profesores, (47).

Salovey, P. y Mayer, J. D. (1990). Emotional intelligence. Imagination, cognition and personality, 9(3), 185-211.

SEP, (2015) Perfil, parámetros e indicadores para Docentes y Técnicos Docentes de Educación Básica. Tomado de http: / / servicioprofesionaldocente.sep.gob.mx/ba/parametros indicadores/

SEP. (2017) Nuevo modelo educativo. Tomado de https://www. gob.mx/sep/documentos/nuevo-modelo-educativo-99339 